\title{
Contribution to the taxonomic knowledge of Ampharetidae (Annelida) from Antarctica with the description of Amage giacomobovei sp. nov.
}

\author{
Stefano SCHIAPARELLI ${ }^{1, *}$ \& Igor A. JIRKOV ${ }^{2}$ \\ ${ }^{1}$ Dipartimento di Scienze della Terra dell'Ambiente e della Vita (DISTAV), Università di Genova, \\ C.so Europa 26, I-16132, Genova, Italy. \\ ${ }^{1}$ Museo Nazionale Dell'Antartide (MNA, Sede di Genova), Viale Benedetto XV No 5 , \\ I-16132, Genova, Italy. \\ ${ }^{2}$ Department of General Ecology and Hydrobiology, Biological Faculty, Leninskiye Gory, 1, \\ building 12, Moscow State University, Moscow, 119234, Russia. \\ *Corresponding author: stefano.schiaparelli@unige.it \\ ${ }^{2}$ Email: ampharete@ya.ru \\ ${ }^{1}$ urn:1sid:zoobank.org:author:D5CF0ED9-9A7C-45D4-B4E1-895D56CA160A \\ ${ }^{2}$ urn:lsid:zoobank.org:author:C611DB01-CF14-4549-B2D8-24D498D9859A
}

\begin{abstract}
Thanks to newly collected material from the Terra Nova Bay area (Ross Sea, Antarctica), we discuss the taxonomy of the ampharetid genera Amage Malmgren, 1866 and Amythas Benham, 1921. A new species of Amage, A. giacomobovei sp. nov., is described based on morpho-anatomical data. This is the second new species described from an area which appears to be rich in ampharetids, a coastal embayment at $\sim 500 \mathrm{~m}$ depth near the Italian "Mario Zucchelli" research station. The new species is characterized by having 16 abdominal uncinigers and four pairs of branchiae that readily distinguish it from its congeners. Tubes of $A$. giacomobovei sp. nov. are also characteristic in showing a large amount of embedded sponge spicules, suggesting a possible close association to spicule mats. Based on the amended diagnoses of the two genera, Amage septemdecima Schüller \& Jirkov, 2013 is transferred to the genus Amythas. Finally, to simplify the task of ampharetid genera recognition for untrained people, we provide a dichotomic key for ampharetid genera found in Antarctica and a checklist of species occurring in Terra Nova Bay.
\end{abstract}

Keywords. Amage, Ampharete, Ross Sea, morphology, ecology, distribution, dichotomic key.

Schiaparelli S. \& Jirkov I.A. 2021. Contribution to the taxonomic knowledge of Ampharetidae (Annelida) from Antarctica with the description of Amage giacomobovei sp. nov. European Journal of Taxonomy 733: 125-145. https://doi.org/10.5852/ejt.2021.733.1227

\section{Introduction}

Ampharetids are tube-dwelling, deposit feeder polychaetes (Fauchald \& Jumars 1979; Jumars et al. 2015), with a few examples of suspension feeder species (Gruia \& Manoleh 1974). The group is globally distributed, even in freshwater, but is typically found at high latitudes and in deep-sea environments. 
In Antarctica this group shows very high densities and diversity (Wlodarska-Kowalczuk et al. 2007; Grange \& Smith 2013) with many species only recently described (Schüller 2008; Schüller \& Jirkov 2013; Schiaparelli \& Jirkov 2016), suggesting that many more species are waiting to be discovered.

In this paper we discuss the taxonomy of the ampharetid genera Amage Malmgren, 1866 and Amythas Benham, 1921, emend the description of its type species, A. membranifera Benham, 1921, and describe a new species of Amage. This new taxon was found in an embayment at $\sim 500 \mathrm{~m}$ deep (nicknamed "the canyon"), located at the centre of the Gerlache Inlet (Terra Nova Bay), which seems to act as a natural sink for the organic matter produced during Austral summer months. From this same site we have already described another species from this family, Amphicteis teresae Schiaparelli \& Jirkov, 2016. Finally, we provide a dichotomic key for ampharetid genera occurring in Antarctica, with a particular focus on those species occurring in Terra Nova Bay, part of a species inventory in the framework of research projects of the Italian National Antarctic Research Program (PNRA).

\section{Material and methods}

\section{Taxon sampling}

The material analysed herein were collected in the Terra Nova Bay area (Supp. file 1), off Mario Zucchelli Station $\left(74.70000^{\circ} \mathrm{S}, 164.1166700^{\circ} \mathrm{E}\right)$, in a deep depression nicknamed "the canyon", during two different expeditions of the Italian National Antarctic Research Program (PNRA): the XXVIII ${ }^{\text {th }}$ (2012-2013) and the XXIX ${ }^{\text {th }}$ (2013-2014). Materials from these expeditions were studied in two different research projects, i.e., "BAMBi" (Barcoding of Antarctic Marine Biodiversity, PNRA 2010/ A1.10) and "ISOBIOTOX" (stable ISOtope and molecular markers for the reconstruction of Antarctic trophic webs under the sea-ice influence: evaluation of robustness to BIOdiversity loss and heavy metals bioaccumulation-neuroTOXicity, 2013-AZ1.16).

The type material, herein described, was obtained through a pelagic SHPN net (Small Hamburg Plankton Net, Hydrobios, Germany) which accidentally hit the bottom instead of remaining in the water column. The SHPN opening was of $1 \mathrm{~m}^{2}$, with a mesh size of $2 \mathrm{~mm}$. These specimens were obtained by sorting the accidentally collected benthic material (roughly $1 \mathrm{~m}^{3}$ ). Specimens of Amythas membranifera were collected the following year, at the same site, by the "ISOBIOTOX" project. In this case, samples were obtained by using a rectangular dredge (mouth $40 \times 20 \mathrm{~cm}$, with $1 \mathrm{~cm}$ mesh at the cod end).

\section{Photography and laboratory analyses}

Collected specimens were immediately placed in $1^{\circ} \mathrm{C}$ seawater and photographed alive, after having gently opened the tubes with a dissecting scissor. Photographs were taken by using a Nikon D700 reflex camera, equipped with a $105 \mathrm{~mm}$ lens and external, infrared-triggered, flashes (Nikon SBR200). Specimens were then fixed in $95 \%$ ethanol or frozen for molecular and isotopic analyses. Supplementary laboratory photos of fixed specimens were later taken with a Leica DFC490 camera, stereo microscope Leica M165C, and compound Leica DMI 4000B microscope at the PP Shirshov Institute of Oceanology of Russian Academy of Science, Moscow. For better contrast specimens were been stained with a solution of methylene blue (not methyl blue), which gives better results than methylene green. For scanning electron microscopy (SEM), specimens stored in $70-75 \%$ ethanol were placed in $100 \%$ ethanol and $100 \%$ acetone, then critical point dried, using $\mathrm{CO}_{2}$ as a transition fluid. After drying, specimens were sputtered with gold for SEM observation. SEM micrographs were taken in a Camscan S-2 Cambridge instrument Scanning Electron Microscope at the M.V. Lomonosov User Facilities Centre (Moscow State University).

\section{Morphological abbreviations}

$\mathrm{AU}=$ abdominal unciniger

$\mathrm{BL}=$ body length 
$\mathrm{BT}=$ buccal tentacles

$\mathrm{C}=$ chaetiger

$\mathrm{NO}=$ nuchal organs

$\mathrm{S}=$ segment

$\mathrm{TC}=$ thoracic chaetiger

$\mathrm{TU}=$ thoracic unciniger (the numbers following the abbreviation refer to the number of the segment, for example TU1 means the $1^{\text {st }}$ thoracic unciniger)

\section{Institution and program abbreviations}

$\mathrm{BMNH}=$ British Museum of Natural History, London, UK

MNA = Italian National Antarctic Museum (Section of Genoa), Genoa, Italy

PNRA = Italian National Antarctic Research Program

HNMI $=$ Hamburg Zoological Museum \& Institute, Hamburg, Germany

\section{Results}

\section{Taxonomy}

Phylum Annelida Lamarck, 1809

Family Ampharetidae Malmgren, 1866

Genus Amage Malmgren, 1866

Paramage Caullery, 1944: 94, type species Paramage madurensis Caullery, 1944.

Egamella Fauchald, 1972: 292, type species Egamella quadribranchiata Fauchald, 1972.

Mexamage Fauchald, 1972: 309-310, type species Mexamage corrugata Fauchald, 1972.

\section{Type species (by monotypy) and type locality}

Amage auricula Malmgren, 1866: 371, pl. XXV, fig. 72.Type locality: Bohuslan, Sweden, 183-220 m ("Koster Bahusiae haud rara prof. 100-120 orgyiar. fundo argill").

Diagnosis (amended)

Prostomium. Prostomium trilobed, middle lobe anteriorly incised or with horns, without longitudinal ridges, with couple of nuchal organs at posterior margin of middle lobe. Lower lip not enlarged and longitudinally grooved.

THORAX. Dorsal ridges absent.

Notopodia. Modified notopodia absent.

Neuropodia. Neuropodia of two types: all thoracic of tori, all abdominal pinnuli, enlarged neuropodia absent.

PALEAE. Paleae usually absent, seldom present, but poorly developed.

BRANCHIAE. 3-4 pairs, if four pairs of branchiae are present, these are arranged nearly segmentally with 2 pairs on segment 3 and 1 pair on each S4 and S5 $(2+1+1)$. When branchiae are in three pairs only, it is the S5 lacking these.

AbDomen. Abdominal rudimental notopodia well developed, but not enlarged. Number of AU 7-21, usually constant for species. 


\section{Remarks}

The presence of nuchal organs has been mentioned for Amage by Moore (1923), Hilbig (2000), Schüller \& Jirkov (2013) and Reuschert et al. (2015). Hilbig (2000) modified the diagnosis of Amage to include NO. However, none investigated the type species of Amage, i.e., Amage auricula Malmgren, 1866. The types of A. auricula are lost (Holthe 1986), but more than 2000 specimens of this species from about 200 localities from the North Polar Basin (see map in Jirkov 2001: 451), including specimens near the type locality, have been investigated. In all these specimens there are well developed NO, well recognizable in the stained specimen reported in Fig. 1B.

Hilbig (2000) and Reuscher et al. (2015) included in generic diagnosis of Amage the presence of smooth buccal tentacles. In the case of the new species herein described, BT are obviously not smooth but, at the same time, this species is beyond any doubt an Amage. Therefore, we consider that the shape of BT cannot be included into the generic diagnosis of Amage. This consideration should also be extended to the definition of other ampharetid genera, as was already suggested by Jirkov (2011).

Jirkov (2011) proposed Egamella Fauchald, 1972, Mexamage Fauchald, 1972, Paramage Caullery, 1944 and Phyllampharete Hartman \& Fauchald, 1971 as junior synonyms of Amage. Reuscher et al. (2015) accepted synonymy of the first three genera but rejected the synonymy of Phyllampharete. We agree with Reuscher et al. (2015) and hence Phyllampharete is not included in the list of Amage synonyms here either.

The taxonomic status of Amage anops perfecta Moore, 1923 is unclear. The author of the species described the status as follows: "This species, at first thought to be distinct under the name A. perfecta, is now regarded as identical with Johnson's species [A. anops] or at most as only a subspecies" (Moore 1923: 210) and a taxon never described as new species. Since then, the type material has not been reexamined.

A list of species (23 in total) belonging to the genus Amage as above diagnosed (original names are given; the type species is marked with an asterisk):

Amage anops Johnson, 1901: 424-425, pl. 15, figs 157-161, pl. 16, figs 162-163.

Amage arieticornuta Moore, 1923: 207-210, pl. XVII, figs 14-18.

Amage asiaticus Uschakov, 1955: 378, fig. 140a-d.

*Amage auricula Malmgren, 1866: 371, pl. XXV, fig. 72.

Amage auricula sibogae Caullery, 1944: 92-94, fig. 76.

Amage benhami Reuscher, Fiege \& Wehe, 2009: 21-22, fig. 1a-g.

Amage ehlersi Reuscher, Fiege \& Imajima, 2015: 1107-1108, figs 2a-h, $13 \mathrm{~b}$.

Amage gallasi Marion, 1875: 308.

Amage imajimai Reuscher, 2015: 3-5, fig.1.

Amage longibranchiata Hartman, 1960: 153-154, pl. 17.

Amage longitorus Reuscher, Fiege \& Imajima, 2015: 1108-1109, figs 3a-g, 13c.

Amage micropaleata Schüller \& Jirkov, 2013: 210-213, figs 3-5.

Amage pusilla Verrill, 1873: 319.

Amage scotica Clark, 1952: 19-21, fig. 4.

Amage sculpta Ehlers, 1908: 141-143, pl. XX, figs 1-9.

Amage scutata Moore, 1923: 210-212, pl. XVII, figs 19-24.

Amage tumida Ehlers, 1887: 220-225, pl. 48, figs 10-19.

Egamella quadribranchiata Fauchald, 1972: 295-296, pl. 60, fig. a.

Mexamaqe corrugata Fauchald, 1972: 310-312, pl. 65, figs a-c.

Paramage madurensis Caullery, 1944: 94-97, fig. 76. 
Paramage tasmanensis Holthe, 2000: 63-64, fig. 5.

Sabellides adspersa Grube, 1863: 57-58, pl. VI, fig. 2.

Sabellides delus Chamberlin, 1919: 455-456, pl. 77, fig. 13.

Species removed from the genus Amage as above diagnosed:

Amage septemdecima Schüller \& Jirkov, 2013 (now transferred to Amythas Benham, 1921, see below).

\author{
Amage giacomobovei sp. nov. \\ urn:1sid:zoobank.org:act:DFCD9E3C-9F02-49EF-8FA0-410B23D37A57
}

Figs 1A, C-I, 2-3

Amage sculpta - Benham 1927: 121-123, pl. III, figs 94-99 (non Ehlers, 1908).

Amage benhami - Reuscher, Fiege \& Wehe 2009: 21-22, fig. 1a-g (partim).

\title{
Diagnosis
}

The new species is characterized by having $16 \mathrm{AU}$ and four pairs of branchiae.

\section{Etymology}

This species is dedicated to the Italian piemontese explorer Giacomo Bove (1852-1877, https://en.wikipedia.org/wiki/Giacomo_Bove), lieutenant of the Italian Royal Navy, who joined the Vega expedition of Adolf Erik Nordenskiöld (1878-1879) in search of the North-East Passage. He was the first Italian to attempt to organize an expedition to Antarctica, however, it was not funded due to its prohibitive costs following the union of Italy.

\section{Material examined}

\section{Holotype}

ANTARCTICA 11 spec. $(B L=21 \mathrm{~mm})$; Terra Nova Bay; $74.69478^{\circ} \mathrm{S}, 164.18458^{\circ} \mathrm{E}$; depth $454 \mathrm{~m} ; 24$ Jan. 2013; Vacchi leg.; station: Vacchi 4; XXVIII PNRA Expedition (2012-2013); MNA-06373.

\section{Paratypes}

ANTARCTICA $\bullet 1$ spec. $(B L=22 \mathrm{~mm})$; same collection data as for holotype; MNA-06354 1 spec. (incomplete, $\mathrm{BL}=15 \mathrm{~mm}$ ); same collection data as for holotype; MNA-06374 $\bullet 1 \mathrm{spec}$. $(\mathrm{BL}=20 \mathrm{~mm})$; same collection data as for holotype; MNA-06377 11 spec. $(B L=22 \mathrm{~mm})$; same collection data as for holotype; MNA-07930 1 spec. $(\mathrm{BL}=18 \mathrm{~mm})$; same collection data as for holotype; MNA-07931 • 1 spec. $(B L=14 \mathrm{~mm})$; MNA-07932.

\section{Other material}

ANTARCTICA • 2 specs; McMurdo Sound; opposite Granite Harbour; $-75.933^{\circ}$ S, $164.200^{\circ}$ E; depth 293 m; station: 340; Terra Nova Expedition (1910); BMNH 1928.2.29.2/3, previously identified by Benham (1927) as A. sculpta.

\section{Description}

\section{Holotype}

MEASUREMENTS. BL $=21 \mathrm{~mm}$.

Prostomium. Prostomium with T-shaped middle lobe encircled by inflated lobe (trilobed); middle lobe with eyespots at the posterior corners; couple of NO present along the posterior margin, separated by a narrow gap; without glandular ridges (Fig. 1A). 
BucCAL TENTACLES. Buccal tentacles few, smooth; tentacle upper surface with rows of warts stained with methylene blue much more intensively than other tentacles' surfaces (Fig. 1C).

BRANCHIAE. Four pairs of branchiae, places of attachment of two branchostyles in transversal row, large median gap (equal to several diameters of branchostyles) between groups of branchiae; branchiae gap with longitudinal folds; other two branchostyles form longitudinal line behind the first two; branchostyles cirriform, smooth, without additional structures visible even after staining; anterior outermost branchiae originating from $\mathrm{C} 1$, next from $\mathrm{C} 2$ and posterior branchiae from $\mathrm{C} 3$; anterior innermost branchiae originating from S2.

Nephridial papillae. Nephridial papillae behind notopodia of TU1-TU3; hardly visible even after staining, usually invisible at all.

Paleae. Paleae absent.

Notopodia AND NEUROPODIA. 15 TC; notopodia well developed, slightly flattened throughout body, all with globular lateral cirrus (Fig. 1D-H); elevated or modified notopodia absent; notochaetae organized in two slightly irregular transversal rows, anterior ones shorter (nearly half) than posterior ones; neuropodial tori with uncini from C4 (= TC4) (Fig. 1D), present in 12 thoracic uncinigers; first pair of tori very long, extending far onto ventral side; size of neuropodia gradually decreasing caudally, tori without cirri; all thoracic neuropodia tori, all abdominal pinnuli (Fig. 2G); there are $16 \mathrm{AU}$ with rudimentary notopodia (Fig. 1G, I); thoracic and abdominal uncini similar (Fig. 3).

Pygidium. Pygidium with lateral cirri long and slender (MNA-06377, MNA-07930, MNA-07931, MNA07932) (Fig. 2I), short and stout (MNA-06354) or rudimental (MNA-06373).

TUBE. The tubes of $A$. giacomobovei sp. nov. are characterized by a large amount of sponge spiculae (Fig. 2D-G) and other (less abundant) foreign materials.

Living COLOR (Fig. 2A-C). Body whitish on the ventral side and pale brown on the dorsal one; nuchal organs orange; branchostyles with pair of blood vessels each; there are white strips connecting neuropodia.

\section{Methylene blue staining}

Anterior halves of the lower lip and ventrum of the next S2 or S2 only stained differently from their posterior halves: immediately after staining with dense small dark blue patches, later when the stain moves inside the body, patches are still dark, while the stain from the posterior halves dissolves. There is a dark violet or blue band between notopodia ventrally (except for one-two last thoracic segments) (Fig. 1E). Parapodia and ridges connecting notopodia and neuropodia (both thoracic and abdominal) (Fig. 1G) and branchiae (Fig. 1E) stained more or less intensively than the rest of the body. A scattered distribution of small intensively stained spots, denser in neuropodia. Spots form narrow strips behind bands connecting neuropodia (Fig. 1H).

\section{Differential diagnosis}

Only four species of Amage have $15 \mathrm{TC}$ and $12 \mathrm{TU}$, but they differ by smooth buccal tentacles (not known for A. tasmanensis) and the number of AU. Amage imajimai described off Japan from a depth of 990-1060 m and A. tasmanensis described from Tasman Sea (3830 m deep) have 11 AU. Amage imajimai has thoracic uncini with two rows of teeth and abdominal uncini with several rows of teeth. Amage tasmanensis has both thoracic and abdominal uncini with a single row of teeth. Amage longitorus described off Japan from a depth of 1060-3016 m has 12 AU, and three pairs of branchiae instead 16 AU and four pairs of branchiae. Amage benhami known from a bioherm off Oregon coasts (North East 


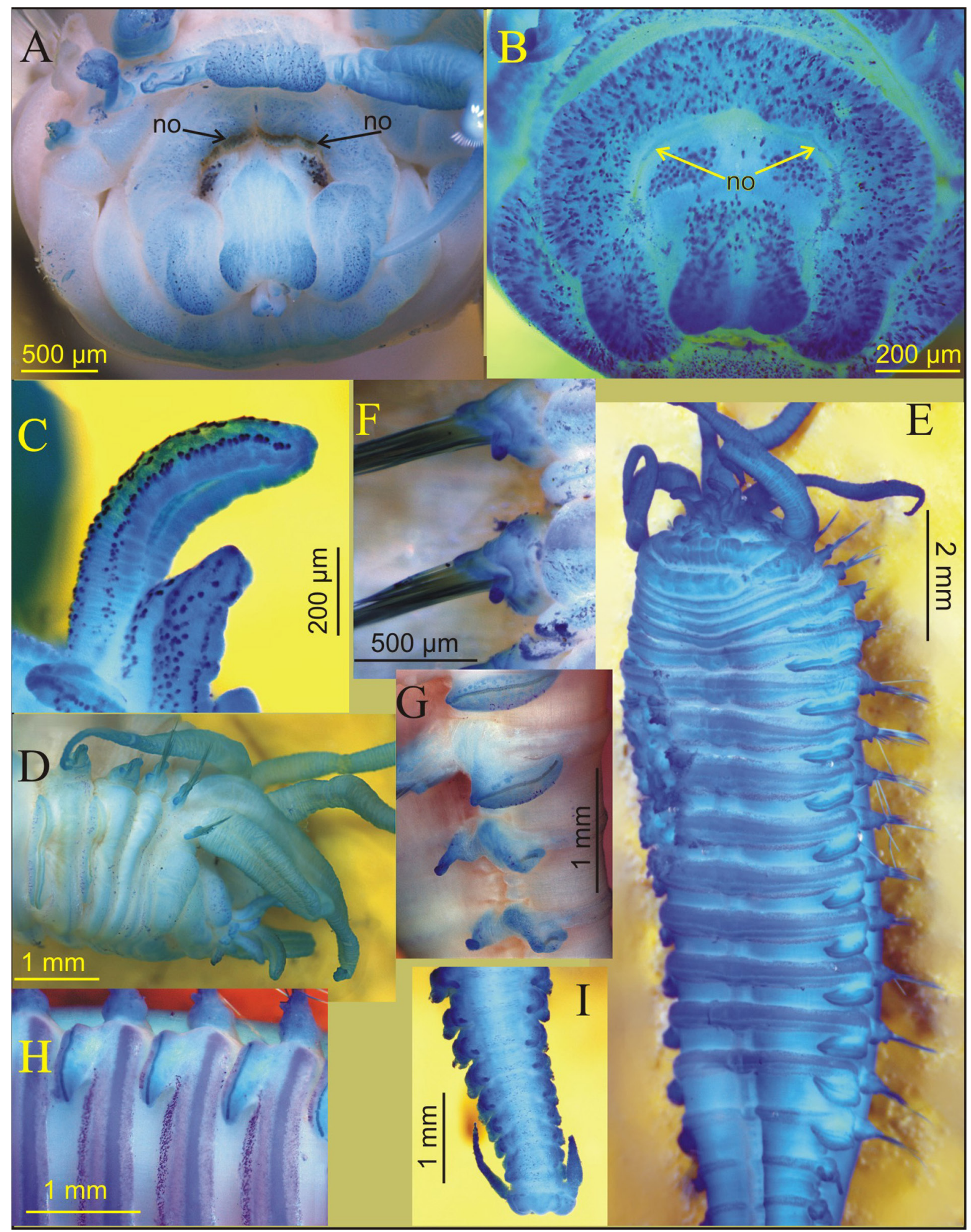

Fig. 1. A, C-I. Amage giacomobovei sp. nov., morphology. A. Paratype (MNA-07931). C-E, G-H. Paratype (MNA-06377). F, I. Paratype (MNA-07931). B. Amage auricula Malmgren, 1866, SP$2274,74.633^{\circ},-164.500^{\circ}, 465 \mathrm{~m}$; arrows indicate the well-developed NO. A-B. Antero-dorsal view of prostomium. C. Buccal tentacles. D. Lateral view. E. Ventral view. F. Dorsal view of middle notopodia. G. Ventral view of last thoracic and first abdominal parapodia. H. Ventral view of middle thorax, showing details of staining pattern. I. Dorsal view of posterior end. Abbreviations: see Material and methods. 


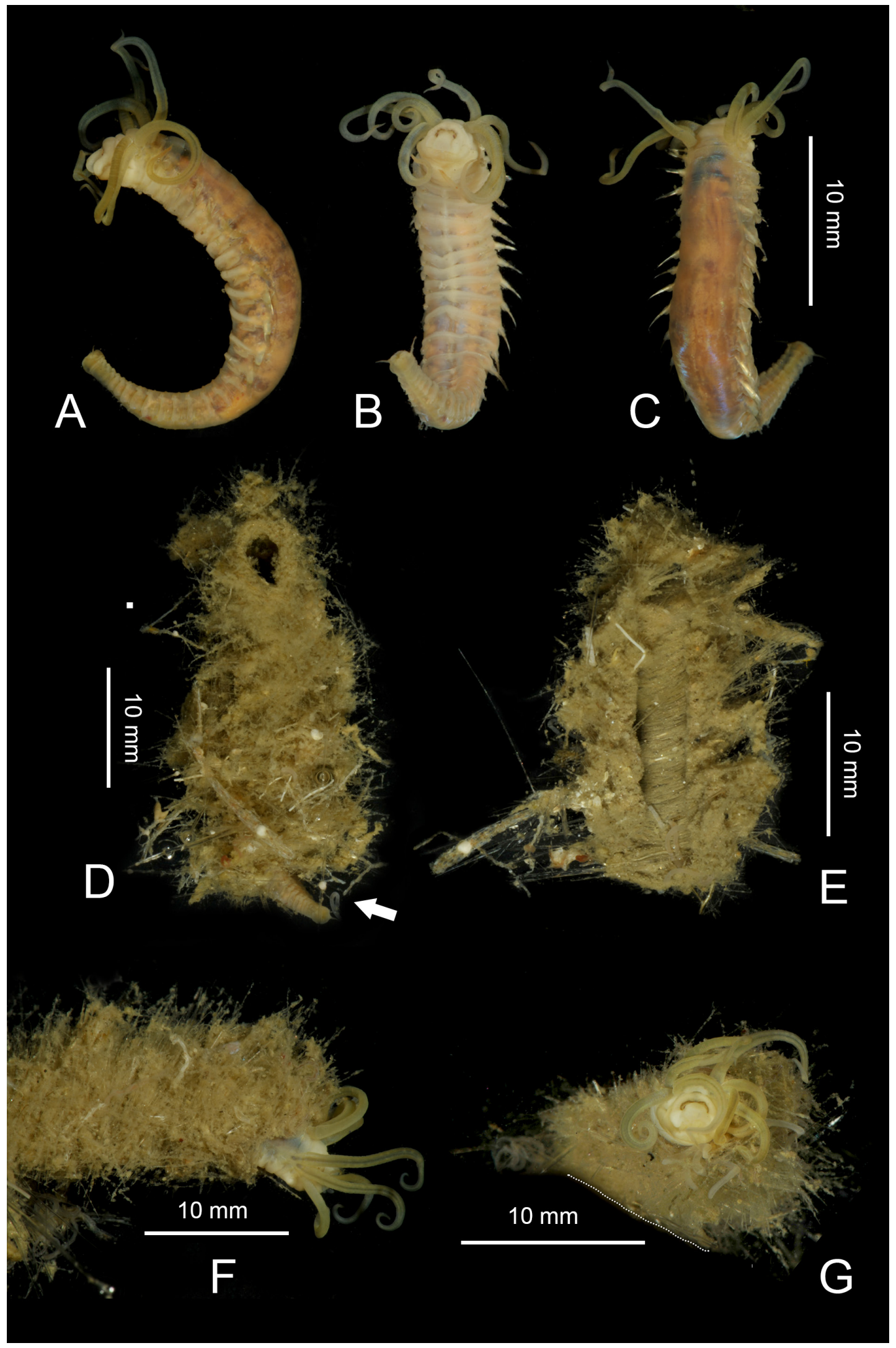

Fig. 2. Amage giacomobovei sp. nov., morphology. A-C. Lateral, ventral and dorsal views of the holotype (MNA-06373). D-E. Morphology of the tube. F-G. Paratype (MNA-06374). 
Pacific, $44.669100^{\circ},-125.111417^{\circ}$, depth $625 \mathrm{~m}$ ), has $15 \mathrm{AU}$ instead of $16 \mathrm{AU}$. Amage benhami also differs in the shape of thoracic (each uncinus has a single row of teeth) and abdominal uncini (each uncinus has numerous teeth arranged in three non-parallel vertical rows), while in A. giacomobovei sp. nov. both thoracic and abdominal uncini are similar.

Specimens of Amage (BMNH 1928.2.29.2/3) found in McMurdo Sound at -75.9333 S, 164.2000 E, 293 m, identified by Benham (1927) as A. sculpta and by Reuscher et al. (2009) as A. benhami, have

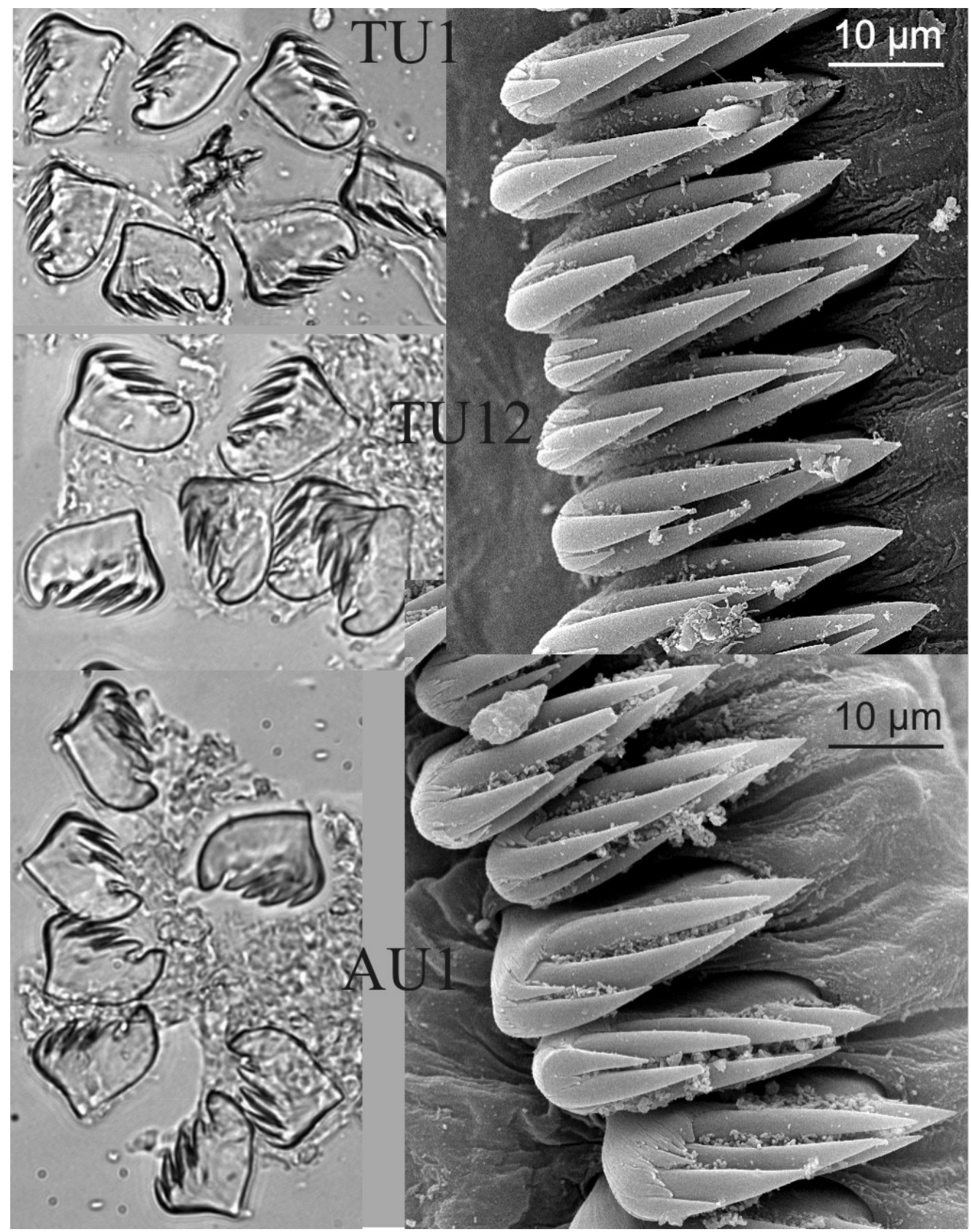

Fig. 3. Amage giacomobovei sp. nov., uncini. Uncini of appropriate chaetigers (TU1, TU12, AU1), compound microscope (MNA-07931) and SEM (MNA-06377) photos. Abbreviations: see Material and methods. 
$16 \mathrm{AU}$ as it was correctly reported by Reuscher et al. (2009) and thus belong to $A$. giacomobovei sp. nov., not to A. benhami.

\section{Distribution}

Only known from the Ross Sea (Antarctica) in 290-500 m.

\section{Remarks}

Benham (1927) described the tubes of $A$. giacomobovei sp. nov., which he considered to be $A$. sculpta, as filled with sponge spicules: "The tube if of grey mud with abundant sponge spicules embedded and foreign bodies adherent. The tube measures $35 \mathrm{~mm}$. by $4 \mathrm{~mm}$. at its upper end. The contained worm is $15 \mathrm{~mm}$. in length". Although no data are available about the bottom type where our specimens and those examined by Bentham were collected, it seems probable, given the high amount of sponge spicules embedded in the tube walls, that this species might be typically occur only associated to "spicule mats" fields (Gutt et al. 2013). Amage giacomobovei sp. nov. tubes are also quite similar to those of $A$. auricula, type species of the genus, which occurs in the North Polar Basin and North Sea. The high level of variation in pygidium later cirri shape is probably the result of different levels of contraction of cirri due to fixation.

Genus Amythas Benham, 1921

\section{Type species (by monotypy) and type locality}

Amythas membranifera Benham, 1921. Type locality: Commonwealth Bay (Antarctica), 325 fathoms (594 m).

\section{Diagnosis}

Prostomium. Prostomium of Ampharete-like, subdivided by a U-shaped groove; median lobe anteriorly rounded; nuchal organs and ridges absent; lower lip not enlarged and longitudinally grooved; nephridial pores/papillae not visible.

THORAX. Dorsal ridges absent.

Notopodia. Modified notopodia absent.

NEUROPODIA. Neuropodia of single type, their uncini generally similar, enlarged neuropodia absent.

\section{Remarks}

Jirkov (2011) proposed the inclusion of Amythas in Neosabellides Hessle, 1917 with certain doubts. However, the new material from Antarctica available for this study clarifies the position of Amythas, which is here considered valid, and its type species redescribed. The status of Neosabellides has been clarified earlier (Jirkov 2018).

Amythas has an Ampharete-like prostomium but it differs from all other known genera of Ampharetinae Malmgren, 1866 by the following combination of characters: i) absence of nephridial pores/papillae behind branchiae; ii) middle lobe of prostomium anteriorly rounded; iii) absence of nuchal ridges and any other structures of the prostomium; iv) thoracic and abdominal neuropodia of the same shape; v) absence of modified notopodia; vi) absence of dorsal ridges; vii) absence of enlarged neuropodia; viii) uncini of thoracic and abdominal neuropodia with similar morphology. 
The genus Amythas also differs from Ampharete Malmgren, 1866 by the absence of a pair of nephridial papillae behind branchiae. In this aspect Amythas is close to Amage, and that is why Amythas septemdecima Schüller \& Jirkov, 2013 was initially placed in Amage. Due to the above considerations, Amage septemdecima (Schüller \& Jirkov, 2013) is here transferred to the genus Amythas due to the combination of characters such as the shape of prostomium, the absence of nephridial papillae behind the branchiae, the similarity of uncini and neuropodia throughout the body and the absence of any specific characters of thorax. This is in accordance to Reuscher et al. (2015), who disagreed with the fact that $A$. septemdecima could be settled in Amage.

Amythas membranifera Benham, 1921

Figs 4, 5A-E, J-L

Amythas membranifera Benham, 1921: 102-105, pl. 10, figs 124-132.

Amythas membranifera - Monro 1939: 141-142, fig. 24.

\section{Material examined}

ANTARCTICA $\bullet 1$ ○(BL $=55 \mathrm{~mm}, 20 \mathrm{AU})$; Terra Nova Bay; $-74.67597^{\circ} \mathrm{S}, 164.24592^{\circ} \mathrm{E}$; depth 400 m; 30 Jan. 2014; Schiaparelli leg.; station: DR5; XXIX PNRA expedition (2013-2014); MNA$07940 \bullet 1$ ठ $(\mathrm{BL}=55 \mathrm{~mm}, 19 \mathrm{AU})$; same collection data as for preceding; MNA-07939 1 के $(\mathrm{BL}=$ $13 \mathrm{~mm}, 17 \mathrm{AU})$; same collection data as for preceding; MNA-07935 $1 \mathrm{o}^{\lambda}(\mathrm{BL}=45 \mathrm{~mm}, 18 \mathrm{AU})$; same collection data as for preceding; MNA-07934 1 spec., undetermined sex; Princess Elizabeth Land; $-67.05000^{\circ}, 74.48333^{\circ}$; depth $437 \mathrm{~m}$; station: 103; BMNH 1941.3.3.126-127.

\section{Description}

Body. Body (Fig. 4A-C) short and thick. Length 13-55 mm, width 9-20 mm; girth of body spindleshaped, increasing to the middle of thorax, decreasing thereafter.

Prostomium. Prostomium trilobed, middle lobe anteriorly broadly rounded; any additional structures (nuchal organs, ridges, horns etc.) absent.

BuCCAL TENTACLES. Buccal tentacles numerous, short, smooth, attached behind a large-folded membrane. Lower lip broad, embracing mouth laterally and slightly latero-dorsally, covered by warts. Paleae totally absent.

BRANCHIAE. Three pairs of branchiae, the outermost one originating from TC1, the innermost one from TC2, and the middle one from S2 (Fig. 5C). Branchostyles cirriform, short, organized in a straight line and showing a wide middle gap. Branchostyles and branchophores covered with warts. There are no visible nephridial papillae or nephropores.

NotOPODIA AND NEUROPODIA. 17 TC, notopodia with capillary chaetae from S3; anterior notopodia small, increasing in size from first to third pair; elevated or modified notopodia absent; $14 \mathrm{TU}$, all thoracic neuropodia well developed, with almost equal size, middle ones slightly bigger than anterior and posterior ones. Ventral shields distinct anteriorly and completely disappearing before the end of thorax. Subdivision of thorax absent. 17-20 AU; shape of neuropodia gradually changing throughout in most specimens, from tori to pinnula with marked size reduction on the thorax/abdomen transition; uncini at the margin of neuropodia. All neuropodia without cirri; typically rudimental abdominal notopodia absent. 


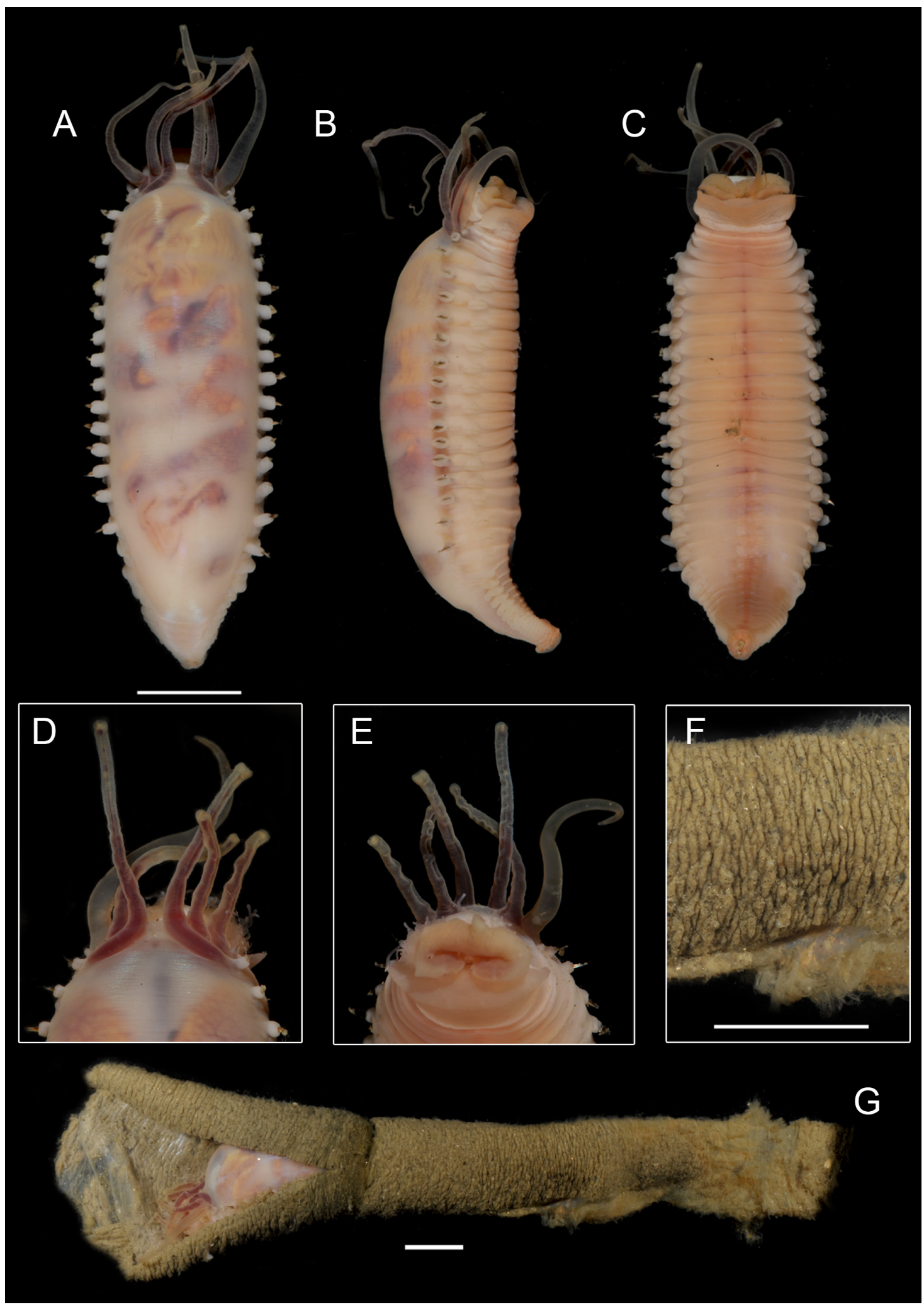

Fig. 4. Amythas membranifera Benham, 1921, morphology (MNA-07940). A-C. Lateral, ventral and dorsal views. D. Dorsal anterior end with a close-up view of the branchiae. E. Ventral view of the anterior end showing the mouth. F. External surface of the tube wall. G. Living specimen still embedded in the tube, partially cut with scissors before the extraction of the specimen. Scale bars $=10 \mathrm{~mm}$. 
UNCINI. Uncini pectinate (Fig. 5J-L) with 4 teeth in double row, similar from TU1 to last AU; prow absent.

PygidIUM. Anal cirri absent.

TUBE (Fig. 4F-G). Tubes of this species appear to be formed by progressive additions of small quantities of homogeneous fine-grained sediment to form an irregular banded pattern (Fig. 4F). The interior part of

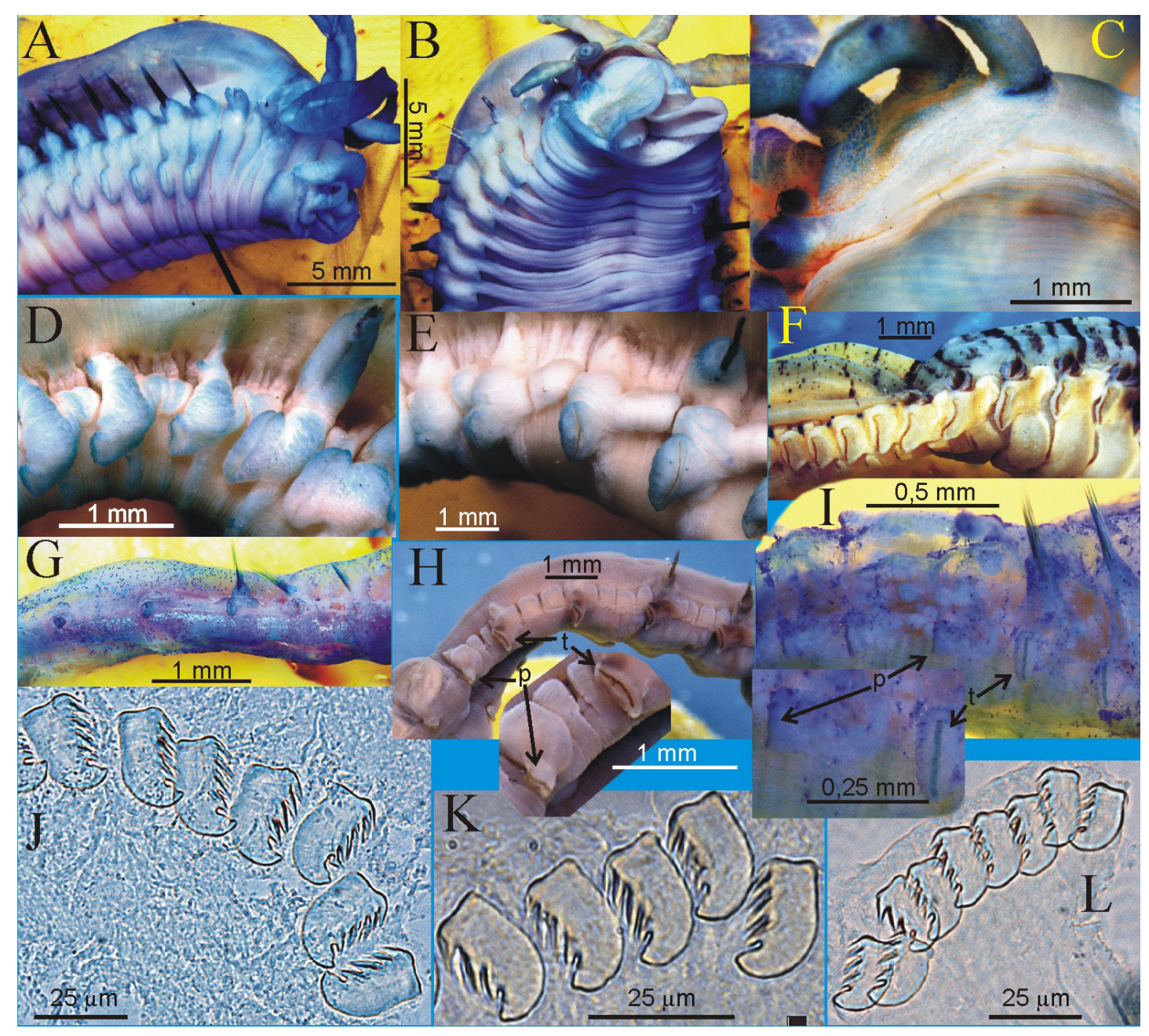

Fig. 5. Amythas membranifera Benham, 1921 and some other Ampharetidae Malmgren, 1866, morphological features. A. Lateral view of A. membranifera (MNA-07490). B. Antero-ventral view of A. membranifera (MNA-07939). C. A. membranifera, dorsal view, showing places of branchostyles attachments and their origin (MNA-07935). D-I. Lateral view of last TC and anterior AU, showing change of neuropodial shape at thorax/abdomen border in different species of Ampharetidae. D. A. membranifera (MNA-07935). E. A. membranifera (MNA-07940). F. Phyllocomus sovjeticus (Annenkova, 1937), Aniva Bay, Japan Sea. G. Samythella elongata Verrill, 1873, R/V "Vitjaz", station 5624, 45 $26^{\prime}$ N, $154^{\circ} 12^{\prime}$ E, depth 5200 m. H. Ampharete finmarchica (M. Sars, 1865), R/V "Schmidt", station 26.9301, 69.91667 ${ }^{\circ} \mathrm{N}, 41.98333^{\circ} \mathrm{E}$, depth $107 \mathrm{~m}$. I. Amage auricula Malmgren, 1866, Ice station SP-22, st. $74,74.633^{\circ} \mathrm{N},-164.500^{\circ} \mathrm{E}$, depth $465 \mathrm{~m}$. J-L. Uncini of A. membranifera. J. From TU1. K. From AU1. L. From AU2 (last). Abbreviations: $\mathrm{p}=$ pinnuli; $\mathrm{t}=$ tori. 
the tube has a homogeneous and transparent membranous lining that isolates the body of the worm from the outer layer and that can easily be peeled off from it (Fig. 4G).

\section{Distribution}

This species was reported from fjords along the West Antarctic Peninsula (WAP) (Grange \& Smith 2013) and in several stations from the Ross Sea (NZ NIWA "IPY-CAML" Voyage TAN0802; records retrieved from GBIF, last accession 2020 Feb. 20).

\section{Remarks}

Benham in the description of the new genus Amythas, stated that there were no buccal tentacles and that these were replaced by a folded membrane (Benham 1921). Hartman (1966) and Fauchald (1977) followed Benham. As it has already been stated by Monro (1939), buccal tentacles are present in Amythas as in all other Ampharetidae. The whole construction of buccal tentacles shows perfect resemblance to Terebellidae Johnston, 1846 and, at the same time, to Ampharetidae with an everted pharynx (see Jirkov 2016: fig. 3) which provides an indication of their homology and prostomial origin. The position of the uncini at the margin of the neuropodia was found to vary according to the individuals (e.g., Fig. 5D-E). The smallest specimen examined (MNA-07935) has small rudimental abdominal notopodia and AU neuropodia more pinnuli-like (Fig. 5D). The morphology of the tube of this species was documented and described to occur in extant Sabellidae as well as in the ichnofossil Caprascolex antarcticus Schweitzer et al., 2005 from the Antarctic Eocene of La Meseta formation (Seymour Island, Antarctica) (Schweitzer et al. 2005: figs 3b, 4). In situ images of tubes of this species are available in Grange \& Smith (2013: fig. 2c).

\section{Key to Ampharetidae genera occurring in Antarctica}

In order to simplify the task of genera recognition of not trained people we have assembled a dichotomic key hoping that this would speed the recognition of the different Antarctic ampharetid genera.

1. Three or four anterior segments with vertical rows of minute acicular chaetae

Melinninae Chamberlin, 1919 ...2

- Minute acicular chaetae absent Ampharetinae Malmgren, 1866 ...3

2. Hooks (usually one pair) and dorsal crest (usually one and dentate) behind the branchiae present Melinna Malmgren, 1866

- Hooks absent, dorsal crest present ...............................................elinnides Wesenberg-Lund, 1950

- Hooks and dorsal crest absent (= Melinnantipoda) Melinnopsis McIntosh, 1885 (= Amelinna, Melinnexis, Melinnopsides)

3. Buccal tentacles attached outside the mouth, methylene blue staining pattern of ventral glandular shields well marked Noanelia Desbruyères \& Laubier, 1977

- Buccal tentacles attached inside the mouth (seldom may be everted), methylene blue staining pattern of ventral glandular shields poor marked

4. Prostomium Amphicteis-like: with prominent straight transversal nuchal ridges; middle lobe anteriorly more of less incised, usually with pair of longitudinal ridges; rudimental notopodia AU1 several times smaller than normal thoracic Amphicteis Grube, 1850

- Prostomium Ampharete or Amage-like: trilobed, without prominent nuchal organs or ridges; middle lobe anteriorly rounded; rudimental notopodia AU1 several times smaller normal thoracic or absent

- Prostomium without lobes, without prominent nuchal organs or ridges ........................................ 13 
5. Middle lobe of prostomium anteriorly incised or with horns (Fig. 1A-B) ……............................. 6

- Middle lobe of prostomium anteriorly rounded or pointed ........................................................... 8

6. Abdominal neuropodia with very long cirri, longer than width of segment

- Abdominal neuropodial cirri, if present much shorter than width of segment (Fig. 1G)

7. All abdominal neuropodia, including AU1 pinnuli (Fig. 1G), no more than $16 \mathrm{AU}$

Amage Malmgren, 1866

(= Egamella, Mexamage, Paramage, Phyllampharete)

- All abdominal neuropodia pinnula, except AU1, neuropodia AU1 tori (like thoracic), more than 20 $\mathrm{AU}$

Grubianella McIntosh, 1885

8. Distinct transversal dorsal ridge between TC3 and TC4 present

Melinnampharete Annenkova, 1937

(= Eusamytha Hartman, 1967 non McIntosh, 1885, Eusamythella, Neosamytha)

- Dorsal ridge absent

9. One, usually from $5^{\text {th }}\left(4^{\text {th }}-6^{\text {th }}\right)$ to the last pair of posterior notopodia slightly shifted dorsally and connected by low ridge

Anobothrus Levinsen, 1884

- One pair of posterior notopodia (last, $2^{\text {nd }}$ or $3^{\text {rd }}$ from last) flattened and shifted dorsally

- Posterior notopodia neither flattened, nor shifted dorsally, ridges also absent

Sosane Malmgren, 1866

10. $1^{\text {st }}$ segment with 'horns'

Abderos Schüller \& Jirkov, 2013

- $1^{\text {st }}$ segment without 'horns'

11. Lower lip enlarged, longitudinally grooved

Lysippe Malmgren, 1866

(= Lysippides, Paralysippe, Pseudampharete, Pterolysippe, Samytha)

- Lower lip not enlarged

12. A pair of nephridial papillae medially behind the branchiae. Paleae well developed, paleal chaetae bigger then most developed notochaetae (paleae of species outside Antarctic may be smaller or even absent) Ampharete Malmgren, 1866

(= Asabellides, Parampharete, Pseudosabellides, Pterampharete, Sabellides, ?Amythasides)

- Nephridial palillae medially behind the branchiae absent (Fig. 4C). Paleae absent

Amythas Benham, 1921

13. Two last pairs of notopodia (or only second counting from the back) slightly shifted dorsally and connected by low, transverse ridges

Zatsepinia Jirkov, 1986

- Dorsally shifted notopodia and dorsal transverse ridges absent

14. Prostomium with pair of tranversal nuchal organs

- Prostomium without nuchal organs

Glyphanostomum Levinsen, 1884

15. The shape of neuropodia slightly changed along the body (Fig. 5B) .......Phyllocomus Grube, 1877

(= Shistocomus, ?Amphisamytha)

- Neuropodia of thorax, AU1, and AU2 are tori, the rest are abdominal pinnuli, change is well marked 


\section{Checklist of species occurring in Terra Nova Bay}

At least 7 different species, based on literature data and vouchers curated at the Italian National Antarctic Museum (Section of Genoa), have been recorded so far in the Terra Nova Bay area: Amage giacomobovei sp. nov., Ampharete kerguelensis McIntosh, 1885, Amphicteis antarctica Hessle, 1917, Amphicteis teresae Schiaparelli \& Jirkov, 2016, Amythas membranifera Benham, 1921, Anobothrus patagonicus (Kinberg, 1866), Sosane kerguelensis (Monro, 1939). A map with the distributional records is reported in Supp. file 1.

\section{Discussion}

The availability of newly collected material from Terra Nova Bay has enabled the description of a second new species of Ampharetidae, Amage giacomobovei sp. nov, after that of Amphicteis teresae, and allowed a better understanding and definition of some morphological characters, that have been debated for a long time, of the genus Amythas.

This peculiar genus differs from all other genera of Ampharetinae in having a unique combination of characters (see Remarks above) that should make its diagnosis straightforward. On the other hand, it is exactly this mix of characters, some of which have 'intermediate' states, which makes the evaluation of the affinities of this genus, compared to other Ampharetidae on a morphological base, difficult. These 'incongruences', for example, lead to the proposal (Imajima et al. 2012) of a new term (i.e., "intermediate uncinigers") to designate segments carrying neuropodia of tori type but avoid of notopodia and notochaetae and, in turn, to a new definition of body regions in Amythas. However, these uncertainties are here reinterpreted and, at the same time, simplified, thanks to the newly available material. Of course, natural affinities and remaining uncertainties could only be solved when molecular data is available to build a robust phylogenetical framework for the family.

One of the main differences between Amythas and other genera is represented by the shape of neuropodia and their uncini. Ampharetidae has two types of neuropodia: tori and pinnuli (Figs 1E, G and 5H-I). Tori have uncini situated in a furrow relatively far from the margin of neuropodia, while pinnuli have uncini exactly at the margin of neuropodia. Tori are bigger and more sessile than pinnuli. In most ampharetid genera anterior neuropodia are tori and posterior are pinnuli. This change is abrupt and often specific for genera.

Amphicteis (Schiaparelli \& Jirkov 2016: fig. 5a-b) and Amage (Figs 1E, G, 5I) have neuropodia on all TU tori and all AU pinnuli. Grubianella always have neuropodia on all TU and AU1 tori and the rest AU pinnuli (Jirkov 2018: fig. 12b). Ampharete (Fig. 5H) and Anobothrus always have neuropodia of all TU and AU1 and AU2 tori, and the rest AU pinnuli. If the number of TU varies within genus, the change from tori to pinnuli always happens between AU2 and AU3. The same situation occurs in Amage: despite the number of TU is variable, all of TU bear tori and all AU bear pinnuli. On the other hand, in Lysippe there are always 14 chaetigers with tori, regardless the number of segments with notopodia. Melinna always has anterior TU tori, while last two are TU and all AU are pinnuli.

This change of types of neuropodia may be accompanied by an abrupt change in the shape of uncini (like in Glyphanostomum, Hypania Ostrooumouff, 1896, Jugamphicteis Fauchald \& Hancock, 1981, Melinnampharete, some Ampharete, Amage and Amphicteis) (Jirkov 2011, 2018; Reuscher et al. 2009). Some other genera such as Phyllocomus (Fig. 5F), Samythella Verrill, 1873 (Fig. 5G) have no such marked transition in neuropodial shape, which instead gradually changes from tori to pinnuli throughout. Since Phyllocomus and Samythella show some characters, such as a prostomium not subdivided into lobes, number of AU large and variable within species, that can be considered plesiomorphic (e.g.), we suggest that the abrupt change in the two types of neuropodia having a fixed position could represent 
an apomorphic character. Although only a robust molecular phylogenetic framework would determine which are the true plesiomorphic and apomorphic characters, these observed changes may serve as working hypotheses to be tested with molecular data in the future. According to this scenario, the morphology of neuropodia could be summarized into three different states:

(1) A plesiomorphic state, where the neuropodia change gradually along the body (e.g., in Phyllocomus, Samythella)

(2) An intermediate state, where the neuropodia change abruptly in fixed places near thorax/abdomen boundary and bear uncini of similar shape throughout the body (e.g., in Anobothrus, Gnathampharete Desbruyères, 1978, Grubianella, Lysippe, Melinna, most Amage, Ampharete, Amphicteis)

(3) An apomorphic state, where the neuropodia are of different type and bear different types of uncini, which also change according to the type of neuropodia (e.g., in Glyphanostomum, Hypania, Jugamphicteis, Melinnampharete, some Amage, Ampharete and Amphicteis).

Abdominal neuropodia of Amythas are similar to pinnuli, but this similarity is not constant since in large specimens uncini are not situated on the margin of neuropodia and remains in poorly developed furrows. The position of this tori/pinnuli change is also not stable (compare Fig. 5D and 5E). Therefore, it could be argued that neuropodia in Amythas represent a transitional stage between the plesiomorphic and apomorphic states: they are in the intermediate state, but this change is not so sharp and stable as in more apomorphic genera such as Ampharete, Amphicteis, Amage, Anobothrus, Grubianella, Jugamphicteis, Lysippe. Uncini also have a similar shape throughout.

This condition is at the base of the choice of Imajima et al. (2012) of proposing the new term "intermediate uncinigers". Imajima et al. (2012) also proposed that only those segments with neuropodial pinnules could be considered as "abdominal uncinigers" (Imajima et al. 2012: 76-77). Thus, in genera as Ampharete, Anobothrus, Grubianella, Lysippe, the body should be subdivided into thorax, transitional segments, and abdomen. This division, however, is unjustified for several reasons. For example, in Melinna Malmgren, 1866 and Orochi Reuscher, Fiege \& Imajima, 2015 some posterior thoracic neuropodia are pinnuli. Therefore, by following their proposal, these posterior thoracic segments should be called transitional as well, despite they remain in the opposite direction.

Moreover, in some genera of Ampharetidae, such as Phyllocomus, Samythella and Amythas, the change of neuropodial shape is gradual, not sharp, and all segments (even thoracic ones) bear neuropodial pinnules (apomorphic state). By applying Imajima et al. (2012) scheme the logical base for subdivision the body on thorax and abdomen would be lost and the whole thorax area would remain undefined. Similar situation occurs in Terebellini and Artacamini (sensu Jirkov 2001) where some anterior abdominal segments can have neuropodia similar to posterior thoracic ones (double-row tori), while the rest abdominal segments have pinnuli like posterior segments of Ampharetidae or tori, but singlerow. The number of such anterior abdominal segments can vary from zero or few to several tens and sometimes almost all, but few posterior most abdominal segments have double-rows neuropodia. The same occurs in some Polycirrinae Malmgren, 1866 that have no parapodia at all but that should be called transitional as well, according to the Imajima et al. (2012) scheme. Given the above points, the Imajima et al. (2012) proposal of a new terminology seems unjustified and impossible to be applied in the practice. Therefore, it is here proposed to continue to use a simple and practical division, where the thorax area is defined by segments having notopodia with notochaetae and the abdomen by segments without notopodia with chaetae.

Other differences between Amythas and other genera lie in the shape of the prostomium. Amythas has a prostomium subdivided by a U-shaped groove and a rounded middle lobe as most of 'Ampharete-like' 
Ampharetinae. It differs from 'Amage-like' genera (such as Grubianella, Hypania and Samythopsis), which have an U-shaped groove, but also a middle lobe incised or even bearing horns.

Most of the genera with an Ampharete-like prostomium have peculiar traits: Eclysippe Eliason, 1955 and Auchenoplax Ehlers, 1887 have thorax sharply subdivided into two regions; Anobothrus and Sosane have modified notopodia in posterior thorax, Melinnampharete has transversal dorsal ridge between TC3 and TC4, Lysippe has lower lip enlarged, longitudinally grooved, Gnathampharete has numerous jaws. Only Amythas has none of these specific traits.

The above list of Amythas characters, when compared to those of similar genera should avoid further uncertainties in the identification of this genus, although many of these traits are not easily weighted by non-experts.

\section{Acknowledgements}

We thank the Italian National Antarctic Research Program (PNRA) for the funding of the "BAMBi" (2010-A1.10) and "ISOBIOTOX" (2013-AZ1.15) projects and the State Research Program granted to Moscow State University (project Patterns in structure and functioning of biological communities No. 15-5-21 General Ecology and Hydrobiology Dept) for the financial support to I. Jirkov. Dr Andrev Sazhin (IORAN) provided use of a stereo microsope and compound microscope for photography. The SEM was performed with financial support from the Ministry of Education and Science of the Russian Federation. We thank Marino Vacchi, for having been made available to the project "BAMBi" the material accidentally collected with the SHPN. We also thank Dr H.J. Griffiths (BAS) for the English revision. Two anonymous reviewers are acknowledged for their comments that greatly improved the first version of the manuscript.

\section{References}

Benham W.B. 1921. Polychaeta. Australasian Antarctic Expedition 1911-1914, Scientific Reports, Series C - Zoology and Botany 6 (3): 1-128. Australasian Antarctic Expedition, Sydney. Available from https://doi.org/10.5962/bhl.title.16201 [accessed 22 Jan. 2021].

Benham W.B. 1927. Polychaeta. British Antarctic 'Terra Nova' Expedition Natural History Reports, Zoology 7 (2): 47-182. British Museum (Natural History), London.

Caullery M. 1944. Polychètes sédentaires de l'Expédition du Siboga: Ariciidae, Spionidae, Chaetopteridae, Chlorhaemidae, Opheliidae, Oweniidae, Sabellariidae, Sternaspidae, Amphictenidae, Ampharetidae, Terebellidae. Siboga-Expeditie Uitkomsten op Zoölogisch, Botanisch, Oceanographisch en Geologisch gebied verzameld in Nederlandsch Oost-Indië 1899-1900 24 (2 bis): 1-204. Brill, Leyden.

Chamberlin R.V. 1919. The Annelida Polychaeta [Albatross Expeditions]. Memoirs of the Museum of Comparative Zoology at Harvard College 48: 1-514. Available from https://www.biodiversitylibrary.org/ia/memoirsofmuseumo4801harv/\#page/11/mode/1up [accessed 22 Jan. 2021].

Clark R.B. 1952. New records of sub-littoral polychaetes from the Clyde Sea area, with a description of a new species. Proceedings of the Royal Society of Edinburgh, Section B, Biological Sciences 65 (1): 1-26. https://doi.org/10.1017/S0080455X00000382

Ehlers E. 1887. Reports on the results of dredging, under the direction of L.F. Pourtalès, during the years 1868-1870, and of Alexander Agassiz, in the Gulf of Mexico (1877-78), and in the Caribbean Sea (1878-79), in the U.S. Coast Survey steamer "Blake", Lieut-Com. C. D. Sigsbee, U.S.N. and Commander J.R. Bartlett, U.S.N., commanding. XXXI. Report on the Annelids. Memoirs of the Museum of Comparative Zoology at Harvard College 15: vi \& 335 pp. https://doi.org/10.5962/bhl.title.65639 
Ehlers E. 1908. Die bodensässigen Anneliden aus den Sammlungen der deutschen Tiefsee-Expedition. In: Chun, C. (ed) Wissenschaftliche Ergebnisse der Deutschen Tiefsee-Expedition auf dem Dampfer "Valdivia” 1898-1899 16 (1): 1-168. https://doi.org/10.5962/bhl.title.2171

Fauchald K. 1972. Benthic polychaetous annelids from deep water off western Mexico and adjacent areas in the Eastern Pacific Ocean. Allan Hancock Monographs in Marine Biology 7: 1-575. Available from https://repository.si.edu/handle/10088/6207 [accessed 22 Jan. 2021].

Fauchald K. 1977. The Polychaete Worms. Definitions and Keys to the Orders, Families and Genera. Natural History Museum of Los Angeles County. Science Series, 28. Available from https://repository.si.edu/handle/10088/3435 [accessed 22 Jan. 2021].

Fauchald K. \& Jumars P.A. 1979. The diet of worms: a study of polychaete feeding guilds. Oceanography and Marine Biology: An Annual Review 17: 193-284.

Available from https://repository.si.edu/handle/10088/3422 [accessed 22 Jan. 2021].

Grange L. \& Smith C.R. 2013. Megafaunal communities in rapidly warming fjords along the West Antarctic Peninsula: hotspots of abundance and beta diversity. PLoS ONE 8: e77917.

https://doi.org/10.1371/journal.pone.0077917

Grube A.E. 1863. Beschreibung neuer oder wenig bekannter Anneliden. Sechster Beitrag. Archiv für Naturgeschichte 29: 37-69. https://doi.org/10.5962/bhl.part.9306

Gruia L. \& Manoleh D. 1974. Considerations sur le rôle des algues dans la nourriture des Polychetes reliques ponto-caspiens du Danube. Travaux du Muséum d'histoire naturelle "Grigore Antipa” 15: 2330 .

Gutt J., Böhmer A. \& Dimmler W. 2013. Antarctic sponge spicule mats shape macrobenthic diversity and act as a silicon trap. Marine Ecology Progress Series 480: 57-71. https://doi.org/10.3354/meps 10226

Hartman O. 1960. Systematic account of some marine invertebrate animals from the deep basins off southern California. Allan Hancock Pacific Expeditions 22 (2): 69-216.

Hartman O. 1966 Polychaeta Myzostomidae and Sedentaria of Antarctica. Antarctic Research Series 7. American Geophysical Union, Washington D.C. https://doi.org/10.1029/AR007

Hilbig B. 2000. Family Ampharetidae Malmgren, 1867. In: Blake J.A., Hilbig B. \& Scott P.V. (eds) Taxonomic Atlas of the Benthic Fauna of the Santa Maria Basin and Western Santa Barbara Channel, The Annelida. Part 4. Polychaeta: Fabelligeridae to Sternaspidae 7 (4): 169-230. Santa Barbara Museum of Natural History, Santa Barbara.

Holthe T. 1986. Polychaeta Terebellomorpha. Marine Invertebrates of Scandinavia Vol. 7. Brill.

Holthe T. 2000. Bathyal and abyssal Ampharetidae (Annelida: Polychaeta) (sedentary species II). Galathea Report 18: 57-68.

Imajima M., Reuscher M.G. \& Fiege D. 2012. Ampharetidae (Annelida: Polychaeta) from Japan. Part I: the genus Ampharete Malmgren, 1866, along with a discussion of several taxonomic characters of the family and the introduction of a new identification tool. Zootaxa 3490 (1): 75-88.

https://doi.org/10.11646/zootaxa.3490.1.6

Jirkov I.A. 2001. Polychaeta of the Arctic Ocean. Yanus-K, Moscow.

Jirkov I.A. 2011. Discussion of taxonomic characters and classification of Ampharetidae (Polychaeta). Italian Journal of Zoology 78: 78-94. https://doi.org/10.1080/11250003.2011.617216

Jirkov I.A. 2016. Lysippe nikiti sp. nov. (Polychaeta, Terebellomorpha) from the deep Pacific and Indian Oceans with an amendment to the generic diagnosis of Lysippe. Zootaxa 4117 (1): 125-134.

https://doi.org/10.11646/zootaxa.4117.1.7 
Jirkov I.A. 2018. Redescription of Pavelius uschakovi (Annelida: Ampharetidae). Invertebrate Zoology 15 (4): 340-347. https://doi.org/10.15298/invertzool.15.4.03

Johnson H.P. 1901. The Polychaeta of the Puget Sound region. Proceedings of the Boston Society for Natural History 29 (18): 381-437.

Jumars P.A., Dorgan K.M. \& Lindsay S.M. 2015. Diet of worms emended: an update of polychaete feeding guilds. Annual Review of Marine Science 7 (1): 497-520.

https://doi.org/10.1146/annurev-marine-010814-020007

Malmgren A.J. 1866. Nordiska Hafs-Annulater. Öfversigt af Königlich Vetenskapsakademiens Förhandlingar, Stockholm 22 (3): 355-410.

Available from https://biodiversitylibrary.org/page/32339631 [accessed 22 Jan. 2021].

Marion A.F. 1875. Sur les annélides de Marseille. Revue des sciences naturelles, Montpellier 4 (1): 301-312. Available from http://biodiversitylibrary.org/page/14526461 [accessed 22 Jan. 2021].

Monro C.C.A. 1939. Polychaeta. B.A.N.Z. Antarctic Research Expedition Reports. Series B 4 (4): 87156.

Moore J.P. 1923. The polychaetous annelids dredged by the U.S.S. "Albatross" off the coast of southern California in 1904. IV. Spionidae to Sabellariidae. Proceedings of the Academy of Natural Sciences of Philadelphia 75: 179-259. https://doi.org/10.5962/bhl.title.12425

Reuscher M.G. 2015. Amage imajimai sp. nov., a new species of Ampharetidae (Annelida: Polychaeta) from Japanese waters. European Journal of Taxonomy 154: 1-7. https://doi.org/10.5852/ejt.2015.154

Reuscher M.G., Fiege D. \& Wehe T. 2009. Four new species of Ampharetidae (Annelida: Polychaeta) from Pacific hot vents and cold seeps, with a key and synoptic table of characters for all genera. Zootaxa 2191 (1): 1-40.

Reuscher M.G., Fiege D. \& Imajima M. 2015. Ampharetidae (Annelida: Polychaeta) from Japanese waters. Part IV. Miscellaneous genera. Journal of the Marine Biological Association of the United Kingdom 95 (6): 1105-1125. https://doi.org/10.1017/S0025315415000545

Schiaparelli S. \& Jirkov I.A. 2016. A reassessment of the genus Amphicteis Grube, 1850 (Polychaeta: Amphaetidae) with the description of Amphicteis teresae sp. nov. from Terra Nova Bay (Ross Sea, Antarctica). Italian Journal of Zoology 83 (4): 531-542.

https://doi.org/10.1080/11250003.2016.1259359

Schüller M. 2008. New polychaete species collected during the expeditions ANDEEP I, II, and III to the deep Atlantic sector of the Southern Ocean in the austral summers 2002 and 2005 - Ampharetidae, Opheliidae, and Scalibregmatidae. Zootaxa 1705 (1): 51-68. https://doi.org/10.11646/zootaxa.1705.1.4

Schüller M. \& Jirkov I.A. 2013. New Ampharetidae (Polychaeta) from the deep Southern Ocean and shallow Patagonian waters. Zootaxa 3692 (1): 204-237. https://doi.org/10.11646/zootaxa.3692.1.11

Schweitzer C.E., Feldmann R.M., Marenssi S. \& Waugh D.A. 2005. Remarkably preserved annelid worms from the La Meseta Formation (Eocene), Seymour Island, Antarctica. Palaeontology 48 (1): 1-13. https://doi.org/10.1111/j.1475-4983.2004.00440.x

Uschakov P.V. 1955. Monogoshchetinkovye chervi dal'nevostochnykh morei S.S.S.R. Opredelitely po faune SSSR, izdavaemie Zoologicheskim Institutom Akademii Nauk SSSR. Moscow \& Leningrad. [Polychaeta of the Far Eastern Seas of the USSR. Identification Guides published by Zoological Institute of the Soviet Academy of Science] 56: 1-445. 
Verrill A.E. 1873. XVIII. Report upon the invertebrate animals of Vineyard Sound and the adjacent waters, with an account of the physical characters of the region. Report on the Condition of the Sea Fisheries of the south Coast of New England 1: 295-778. https://doi.org/10.5962/bhl.title.11688

Wlodarska-Kowalczuk M., Sicinski J., Gromisz S., Kendall M.A. \& Dahle S. 2007. Similar soft-bottom polychaete diversity in Arctic and Antarctic marine inlets. Marine Biology 151: 607-616.

https://doi.org/10.1007/s00227-006-0496-9

Manuscript received: 2 July 2020

Manuscript accepted: 17 November 2020

Published on: 8 February 2021

Topic editor: Rudy Jocqué

Desk editor: Pepe Fernández

Printed versions of all papers are also deposited in the libraries of the institutes that are members of the EJT consortium: Muséum national d'histoire naturelle, Paris, France; Meise Botanic Garden, Belgium; Royal Museum for Central Africa, Tervuren, Belgium; Royal Belgian Institute of Natural Sciences, Brussels, Belgium; Natural History Museum of Denmark, Copenhagen, Denmark; Naturalis Biodiversity Center, Leiden, the Netherlands; Museo Nacional de Ciencias Naturales-CSIC, Madrid, Spain; Real Jardín Botánico de Madrid CSIC, Spain; Zoological Research Museum Alexander Koenig, Bonn, Germany; National Museum, Prague, Czech Republic.

\section{Supplementary material:}

Supp. file 1. Map of Terra Nova Bay (TNB) coastline. Pie charts represent the relative abundance (\% of recorded species) of different ampharetids found in three TNB subareas: stations comprised between 0-200 m in Adelie Cove (yellow dots), stations $<400 \mathrm{~m}$ (red dots) and stations $>400 \mathrm{~m}$ (blue dots) north of Adelie Cove, facing the Italian station "Mario Zucchelli" (yellow star). The species Amphicteis teresae Schiaparelli \& Jirkov, 2016 (light blue in the pie chart) and Amage giacomobovei sp. nov. (red colour in the pie chart) do only occur at deeper station in correspondence of an embayment about $500 \mathrm{~m}$ deep (nicknamed "the canyon"), located at the centre of the Gerlache Inlet.

https://doi.org/10.5852/ejt.2021.733.1227.3543 